Author have nothing to disclose with regard to commercial support.

Adulthood, London, United Kingdom," and the editorial commentary by Burkhart and colleagues, "Complex Congenital Aortic Arch Disease: The Need for Mandatory Long-Term Follow-up.'

Belitsis and colleagues ${ }^{1}$ solved the problem in an effective but difficult way for the surgeons and the patient. Fortunately, the patient had a good outcome.

We agree with Burkhart and colleagues ${ }^{2}$ on the long-term follow-up of congenital aortic operated cases to avoid the inherent morbidity and mortality they have.

Related to the report by Belitsis and colleagues, ${ }^{1}$ we agree with Burkhart and colleagues ${ }^{2}$ on a hybrid approach, that is, after a common carotid artery left subclavian artery bypass is performed. To stent the graft pseudoaneurysm, a short covered stent should be used, and if residual significant gradient exists across the aortic arch, an ascending-descending aortic bypass through a median sternotomy should be performed to avoid a hostile dissection field. ${ }^{3}$

State of the art imaging techniques, that is, computed angio-tomography and magnetic resonance angiography, allow us to follow up, diagnose, and treat patients in a way that was unthinkable a few years ago. The availability of recent noninvasive techniques and last-generation devices permits us to manage complex problems in different fields (ie, congenital, degenerative, trauma) ${ }^{4,5}$ and others with less risk. The use of hybrid procedures in cardiovascular surgery has to be in the repertoire of any surgeon, and cooperation with other colleagues is the key for success.

This case illustrates how the cardiovascular global community can interact to discuss information that is useful for everyone.

Romulo Armenta-Flores, $M D$ Victor Arredondo-Arzola, $M D$ Roberto Barba-Padilla, MD Division of Cardiovascular Medicine and Surgery Hospital Aranda de la Parra León, Guanajuato, Mexico

\footnotetext{
References

1. Belitsis G, Finch JR, Shore DF, Rosendahl UP. Pseudoaneurysm at the origin of the left subclavian artery following type A interrupted aortic arch repair in adulthood, London, United Kingdom. J Thorac Cardiovasc Surg. 2016;151:e17-9.

2. Burkhart HM, Thompson JL, Phillips SD. Complex congenital aortic arch disease: the need for mandatory long-term follow-up. J Thorac Cardiovasc Surg. 2016; 151:e19-20.

3. Said SM, Burkhart HM, Dearani JA, Connolly HM, Schaff HV. Ascending-todescending aortic-bypass: a simple solution to a complex problem. Ann Thorac Surg. 2014;97:2041-7.
}

Author has nothing to disclose with regard to commercial support.

4. Roselli EE, Qureshi A, Idrees J, Lima B, Greenberg RK, Svensson LG, et al. Open, hybrid and endovascular treatment for aortic coarctation and postrepair aneurysm in adolescents and adults. Ann Thorac Surg. 2012;94:751-8.

5. Armenta-Flores R, Torres-Cano AF, Sanchez-Lopez JM, Guerrero-Gonzalez H Gunshot to the right carotid trunk: endovascular management. Ann Thorac Surg. 2016;101:e25.

http://dx.doi.org/10.1016/j.jtcvs.2016.02.026

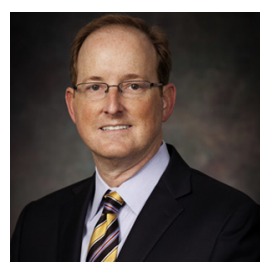

\section{LONG-TERM FOLLOW-UP IS MANDATORY FOR HYBRID APPROACHES TO COMPLEX CONGENITAL HEART SURGERY \\ Reply to the Editor:}

I want to thank Dr Armenta-Flores et al for their perspective on an interesting and challenging congenital cardiac case. It appears that we are all in agreement with regard to: (1) the need for long-term follow-up in adults with congenital heart disease and (2) the need for surgeons to continue to grow and expand their surgical armamentarium when approaching these interesting patients.

Harold M. Burkhart, MD Division of Cardiovascular and Thoracic Surgery University of Oklahoma Health Sciences Center Oklahoma City, Okla

http://dx.doi.org/10.1016/j.jtcvs.2016.04.036

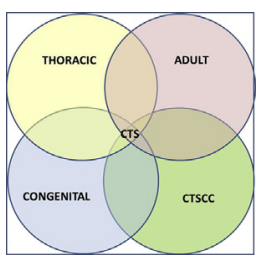

CARDIOTHORACIC

SURGICAL CRITICAL CARE SURGEONS: MANY OF THE FEW

To the Editor:

The editorial commentary by Anderson $^{1}$ is a timely and much appreciated communication. This author is in agreement that a truly complete cardiothoracic surgeon ${ }^{2}$ is fully educated, trained, and skilled in all aspects of cardiothoracic surgical practice, including postoperative management and critical care (Figure 1). As such, they are eligible for certification in whichever area of practice (ie, subspecialty) they choose.

Allowing such choice is precisely what the American Board of Thoracic Surgery has done over the years, with the evolution and flexibility of its mechanisms for certification, and the elimination of the requirement of certification 
Author has nothing to disclose with regard to commercial support.

by the American Board of Surgery, in 2003. This measure, among others, has led to the availability of 4 pathways to certification in thoracic surgery. ${ }^{3}$ An example that is more relevant to the current discussion is the introduction of the mechanisms of certification for congenital cardiothoracic surgery. As with establishing a new subspecialty, a period of transition is to be expected. During this period, the board has recognized those who are fully educated, trained, and experienced surgeons who are dedicated to this particular field of practice and granted them subspecialty certification along a "grandfather" pathway. ${ }^{4}$ A similar measure can be considered for cardiothoracic surgeons who chose cardiothoracic surgical critical care as a career. As the educational curriculum, training, and experiential criteria for this subspecialty matured, this pathway was eventually eliminated. Similarly, cardiothoracic surgeons recognized for an active interest, dedication, and experience in cardiothoracic surgical critical care may serve as transitional program directors for the emerging subspecialty.

Other measures for the establishment of cardiothoracic surgical critical care as a distinct subspecialty are already underway. The broad lines for an educational curriculum have been proposed. ${ }^{5}$ Efforts to establish training and experiential criteria are ongoing, thanks to the Foundation for

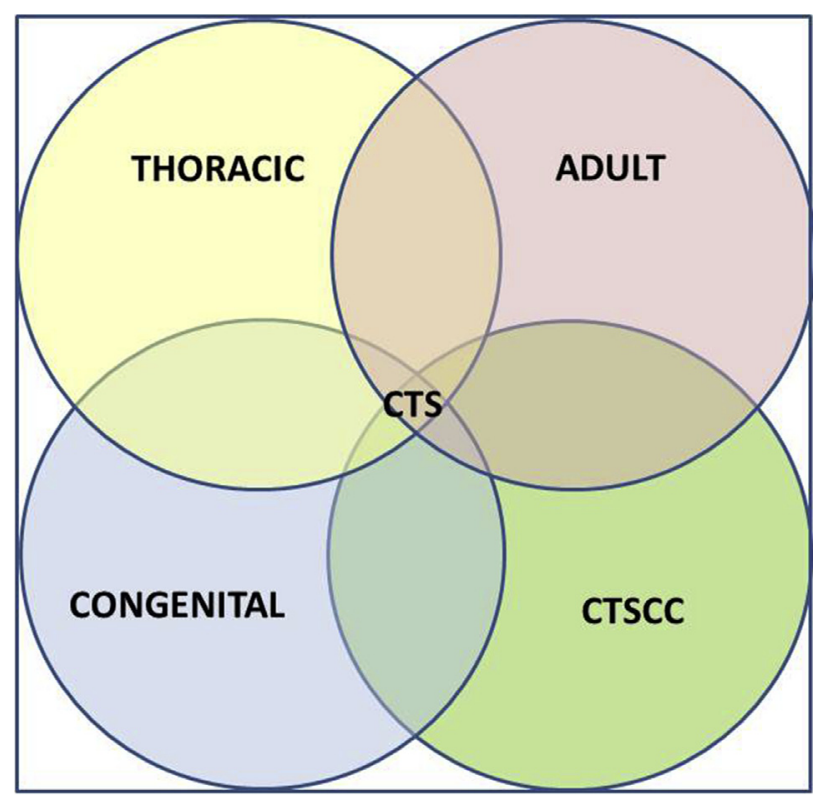

FIGURE 1. Cardiothoracic surgery (CTS) encompasses 4 distinct yet overlapping areas of clinical practice: Adult cardiac surgery, congenital cardiac surgery, noncardiac thoracic surgery, and cardiothoracic surgical critical care (CTSCC). the Advancement of Cardiothoracic Surgical Critical Care conferences, and other symposia, courses, and conferences sponsored by the Society of Thoracic Surgeons, American Association of Thoracic Surgery.

These suggested mechanisms would be beneficial for practicing cardiothoracic surgeons who have chosen cardiothoracic surgical critical care as a career pathway, in obtaining and maintaining privileges in hospitals and clinical institutions. In fact, this approach may be less cumbersome and time consuming than having to enroll in a Critical Care Fellowship with the American Board of Surgery, as is the current situation. We laud these efforts by the American Board of Thoracic Surgery to further advance and promote the leadership role of cardiothoracic surgeons, as they set a most welcome and commendable precedent for professional organizations in the global community.

\section{Hisham M. F. Sherif, MD Cardiac Surgery Christiana Hospital Newark, Del}

\section{References}

1. Anderson ND. Certification in cardiothoracic surgical critical care: a distinction for some or for all? J Thorac Cardiovasc Surg. 2016;152:37-8.

2. Sherif HM. Developing a true cardiothoracic surgeon: professionalism, regulation and the normalization of deviance. Bull Soc Cardiothorac Surg Gr Brit Ireland. Available at: http://www.scts.org/_userfiles/resources/635415439197129609_ SCTS_0714_Bulletin_Final_x1.pdf. Accessed March 1, 2016.

3. American Board of Thoracic Surgery. General requirements for certification. Available at: http://www.abts.org/root/home/certification/general-requirements. aspx. Accessed March 1, 2016

4. American Board of Thoracic Surgery. Congenital cardiac surgery subspecialty certification. Available at: http://www.abts.org/root/home/congenital-cardiacsubspecialty.aspx. Accessed March 1, 2016.

5. Sherif HM. Developing a curriculum for cardiothoracic surgical critical care: impetus and goals. J Thorac Cardiovasc Surg. 2012;143:804-8.

\section{http://dx.doi.org/10.1016/j.jtcvs.2016.03.008}

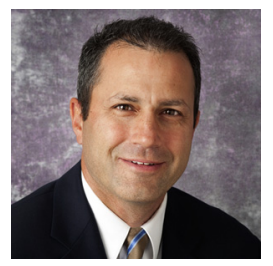

\section{REDEFINING OUR CARDIOTHORACIC SURGICAL INTENSIVE CARE UNITS: CHANGE IS GOOD \\ Reply to the Editor:}

The secret of change is to focus all of your energy, not on fighting the old, but on building the new.

-Socrates

To evaluate fully the evolving nature of critical care in cardiothoracic surgery, it is helpful to take a step back and evaluate how we define our specialty. According to the American Board of Thoracic Surgery, ${ }^{1}$ thoracic surgery "encompasses the operative, perioperative, and surgical critical care of patients with acquired and congenital 